\title{
EL FUTURO REFERÉNDUM EN EL REINO UNIDO DE GRAN BRETAÑA E IRLANDA DEL NORTE SOBRE EL TRATADO QUE ESTABLECE UNA CONSTITUCIÓN PARA EUROPA
}

\author{
SANTIAGO SÁNCHEZ GONZÁLEZ \\ Profesor Titular de Derecho Constitucional
}

En el momento de redactar estas líneas — primeros de enero del año 2005- tan sólo dos de los veinticinco Estados que integran la Unión Europea, Hungría y Lituania, han ratificado la mal llamada Constitución Europea. España lo hará seguramente el próximo día veinte de febrero y, después, tendrán que pronunciarse países como Francia, Polonia, Holanda, Irlanda, Portugal, Luxemburgo, Chequia, Dinamarca, Eslovenia, Bélgica y Alemania. Entre ellos alguno probablemente opte por dar una respuesta negativa. Y lo mismo puede ocurrir en el Reino Unido de Gran Bretaña e Irlanda del Norte.

Es sabido que, prácticamente desde la firma del Tratado internacional por el que se establece una Constitución para Europa ${ }^{1}$, el gobierno laborista del Primer Ministro británico rechazó la idea de celebrar un referéndum para someterlo a la sanción del pueblo británico, arguyendo que el Tratado era poco más que un ejercicio de actualización y sistematización de la normativa existente — a tidying —up exercise-, y que no suponía una alteración sustancial de las relaciones de Londres con Bruselas.

Sin embargo, como consecuencia de la presión popular y de la ejercida por los partidos de la oposición, Tony Blair cambió de criterio y, el pasado 20 de abril de 2004, anunció la celebración del referéndum, con la finalidad exclusiva de ratificar o no el Tratado mencionado. El referéndum tendría lugar después de las próximas elecciones generales, previstas para mayo del año 2005 y, probablemente, en marzo o mayo del año 2006. Hablando de fechas, hay recordar que, a tenor con el artículo IV-447, «el Tratado entrará en vigor el 1 de noviembre de 2006, siempre que se hayan depositado todos los instrumentos de ratificación o, en su defecto, el primer día del segundo mes siguiente al del depósito del instrumento de ratificación del ultimo Estado signatario que cumpla dicha formalidad».

1 Así reza expressis verbis el título otorgado al Tratado en cuestión a pesar de que la naturaleza del texto recogido en el mismo, del proceso de su elaboración y de su contenido, puedan difícilmente considerarse constitucionales. Tal es mi opinión, revisable desde luego, si encontrara argumentos suficientes para hacerlo. 
considerado siempre al margen de otras naciones del 'continente' por razones de historia, costumbres e instituciones, sin mencionar los lazos especiales mantenidos con su antigua colonia. Naturalmente, a partir del momento en que se ha percibido que la relación con Europa podía hacerse muy estrecha, hasta el extremo de recorrer una misma senda constituyente que podría conducir a una integración en una entidad superadora de las viejas naciones-Estados, el pueblo inglés se ha cuestionado sobre la conveniencia o la inconveniencia de dar ese paso pensando, eso si, exclusivamente en su propio interés. Es verdad que un cambio como el que se perfila en el horizonte no es todavía un salto cualitativo que traspase el umbral de las soberanías nacionales, pero para muchos constituye el comienzo de un proceso inexorable, que tiene que generar desconfianza e inquietud, e incluso malestar, entre aquellos sectores de la población que concentran su atención y siguen creyendo en una Inglaterra fiel a su pasado aislacionista.

En ese contexto, hemos presenciado una clara escisión - un cleavage, que dirían los sociólogos- no tanto entre partidos políticos u otras fuerzas políticas y sociales, sino entre los partidarios de una aproximación franca a Europa - aun sin perder las peculiaridades británicas-, y los partidarios de la continuidad de la política exterior inglesa al modo tradicional, como tercero interesado pero plenamente autónomo. La mejor demostración de que, ante esa cuestión, no se ha tratado nunca de un conflicto inter-partidista derivado de las clásicas posiciones ideológicas, es que, en el seno de los dos partidos mayoritarios, el laborista y el conservador, sectores considerables de diputados han roto la disciplina partidista y han mantenido posiciones favorables al otro partido. Así sucedió con motivo de la adhesión a la Comunidad Económica europea en 1971, y así sucede en la actualidad. El recurso al referéndum sobre la continuidad de Gran Bretaña en el mercado común, que se celebraría el 5 de octubre de 1975, fue el medio utilizado por Harold Wilson para salvar la unidad del partido laborista, amenazada por el enfrentamiento entre Roy Jenkins y Anthony Benn. Hoy el recurso al referéndum es también el medio en el que ha pensado Tony Blair para reforzar su posición ante las elecciones generales de la primavera de 2005, muy debilitada sobre todo por la intervención militar en Irak, cuestionada dentro y fuera de su partido, y por la negociación del Tratado por el que se establece una Constitución para Europa.

Los argumentos en favor del Tratado que ahora se invocan, los resumió el propio Blair en la presentación que hizo del Libro Blanco hace cuatro meses: «Por primera vez se recogen en un sólo tratado las competencias, los derechos y deberes de la Unión. Dispone un sistema de voto para el Consejo que es más simple y más equitativo. Fortalece la voz de los gobiernos nacionales dentro de la Unión Europea mediante la creación de un Presidente permanente del Consejo Europeo. Otorga por vez primera a los parlamentos nacionales la competencia de examinar las propuestas dimanantes de la Comisión en la fase de borrador

2 Los demás referendos, de ámbito local, han sido los siguientes: 1-Northern Ireland Border Poll, el 5 de marzo de 1973; 2-Devolution for Scotland, el 1 de marzo de 1979; 3-Devolution for Wales, en la misma fecha que el anterior; 4-Establishment of the Scottish Parliament, el 11 de septiembre de 1997; 5- Establishment of the National Assembly for Wales, el 18 de septiembre de 1997; 6-Establisment of the Greater London Authority, el 7 de mayo de 1998; y 7 - Belfast (Good Friday) Agreement, el 22 de mayo de 1998.

3 En 1894, 1911, 1930 y 1945 sobre concesión del auto-gobierno a Irlanda, reforma de la Cámara de los Lores, establecimiento de un área de libre cambio en el imperio británico, y prórroga de la legislatura, respectivamente. 
El referéndum, caso de que llegue a celebrarse, será el segundo de ámbito nacional ${ }^{2}$ en la historia de Gran Bretaña. El otro, que fue convocado también por un gobierno laborista para decidir si el país continuaba siendo miembro de la Comunidad Europea, acaeció el 5 de junio de 1975. ¿Significa esto que el pueblo británico no es partidario de esta particular forma de democracia directa? Es obvio que, a diferencia de lo que ocurre entre sus herederos allende el Atlántico, los anglosajones de las islas no se sienten inclinados a recurrir a plebiscitos y referendos. El porqué eso es así se encuentra en la historia política inglesa. En realidad, la explicación es bastante simple: los ingleses piensan que el referéndum, como institución de democracia directa $-\mathrm{O}$ semidirecta-, es lisa y llanamente incompatible con el principio fundamental del constitucionalismo inglés, es decir, con la soberanía parlamentaria. Tan es así que, con anterioridad a 1975, en las cuatro ocasiones ${ }^{3}$ en que fue propuesto para adoptar decisiones políticas trascendentes, fue rechazado. En su lugar se acudió a la disolución de la Cámara de los Comunes y a la convocatoria de las correspondientes elecciones, en las que el asunto principal objeto de enfrentamiento en la campaña electoral fue el tema que se pretendía fuera sometido a referéndum.

Por otra parte, en derecho inglés, el referéndum no es un requisito necesario para la ratificación de un tratado internacional. El procedimiento normal por el que discurre la aprobación de convenios internacionales desde los años veinte es el siguiente: firma del Gobierno; sometimiento al Parlamento para información y debate del tratado; aprobación en su caso de una ley para convertirlo en derecho aplicable dentro del Reino Unido; y ratificación por el Ministro de Asuntos Exteriores, que actúa en representación de la Corona.

La ausencia de referendos en la historia británica, y el hecho de que los pocos realizados se hayan celebrado muy recientemente, explica la inexistencia de una norma general que los contemple y que solo se contengan algunas disposiciones relativas a los mismos en la Political Parties Elections and Referendum Act 2000 — conocida con el acrónimo PPERA$\mathrm{Y}$ ello al margen de que cada referéndum nacional requiere una ley que lo prevea.

¿Por qué se ha considerado entonces necesario permitir que sea el pueblo el que tenga la última palabra - en palabras del Premier, to let the people have the final say-, sobre el Tratado que establece la Constitución Europea antes de ratificarlo? Quizás sea porque, después de los estadios recorridos en el proceso de unificación, es la primera vez que se menciona expresamente la idea de una constitución europea, y haya que decidir en alguna medida sobre el lugar de cada Estado en esa Europa unida que se dice querer construir. Quizás, porque algunos quieren zanjar de una vez por todas si Gran Bretaña desea permanecer fiel a su destino de nación-Estado independiente y abandonar cualquier empresa europea común o, por el contrario, ha llegado la hora de caminar de la mano del resto del continente.

Para averiguar lo que realmente sucede, parece oportuno preguntarse sobre lo qué hay detrás del debate suscitado con motivo del referéndum. Porque, en principio, el partido laborista no quería plantearlo; y el partido conservador no lo hizo en su día, cuando se encontraba en el gobierno, con ocasión de la firma del Tratado de Maastricht, que confería competencias nuevas a la Unión Europea.

Lo cual nos conduce inexorablemente al problema de fondo, que no es otro sino el de la relación de Gran Bretaña con el resto de Europa, problema que ha sido durante siglos terreno abonado para la discusión política y el debate nacional, porque Gran Bretaña se ha 
4 Foreword. En: «White Paper on the Treaty establishing a Constitution for Europe. Presented to Parliament by the Secretary of State for Foreign and Commonwealth Affairs», September, 2004, pp.1-2. 
y de devolverlas si no las encuentran satisfactorias. Introduce mecanismos más operativos para la flexibilidad a través del incremento de la cooperación (...). El Tratado deja claramente sentado que la Unión Europea no es ni será un super-Estado federal. Mas bien, establece donde puede y donde no puede actuar la UE, y confirma que la UE es una unión de Estados naciones, que sólo tiene los poderes que le confieren esos Estados. Y frente a los mitos — extendidos en particular en Gran Bretaña-, el Tratado no suprime nuestro escaño en el Consejo de Seguridad de la ONU; no amenaza nuestro control de nuestros suministros de petróleo, ni de nuestro ejército; y no nos obliga a unirnos al euro, ni a subir nuestros impuestos, ni a seguir los dictados de Bruselas en materia de política exterior. Para la decisiones más importantes se requiere la unanimidad. Y Gran Bretaña conserva el derecho a no adoptar las medidas que afecten a nuestras leyes de asilo e inmigración. El Tratado no reduce nuestro poder como nación». ${ }^{4}$

En honor a la verdad, el gobierno laborista no se encuentra solo en su postura de favorecer el sí al tratado. Los liberal-demócratas también lo ven como el instrumento clarificador de los principios y objetivos de la Unión y fortalecedor de sus instituciones. Otras organizaciones político sociales, como el «Centre for European Reform» o «Federal Trust», también lo secundan, aunque no hayan mostrado ni mucho menos un apoyo incondicional

En cuanto a los que propugnan el 'no' al Tratado, entre los que se encuentran el partido conservador, el partido de los verdes, el partido por la independencia del Reino Unido y asociaciones como «Vote no» $\mathrm{y}$ «The Bruges Group», algunos confunden, en una aleación interesada que intoxica a amplios sectores de la opinión pública, la futura respuesta afirmativa a la consulta referendaria con el 'sí' incondicional e irreversible a la plena integración de Inglaterra en Europa. No les preocupa, en este sentido, que el artículo I-60 1. del Tratado establezca que «todo Estado miembro podrá decidir, de conformidad con sus normas constitucionales, retirarse de la Unión».

La pregunta que según todas las fuentes se realizará al pueblo inglés en el referéndum es: «¿Debe (ría) el Reino Unido aprobar el tratado por el que se establece una constitución para la Unión Europea? Anticipar la probable respuesta mayoritaria unos quince meses antes de que se celebre la consulta, es algo que la prudencia desaconseja, pero que puede hacerse asumiendo el riesgo implícito en un vaticinio de ese calibre. Sabemos que hasta diciembre del año 2004 un porcentaje abrumador de las encuestas arrojaba un triunfo sin paliativos del 'no'; pero inclinarse por un resultado de ese tenor, por legítimo que sea con los datos de que se dispone, sería desconocer el condicionamiento de factores tales como las próximas elecciones generales, que servirán a buen seguro como indicador de la orientación más o menos europeísta del electorado inglés, y la influencia de los medios de información y, en particular, de la BBC.

Una última reflexión. Los que se están tropezando con dificultades insuperables para conseguir que su mensaje llegue nítido a la ciudadanía son los que creen en la unificación de Europa con una Inglaterra plenamente integrada, pero no desean apoyar este proyecto concreto de constitución europea. En este punto la analogía con el resto de los países que utilizarán el referéndum es incuestionable. Y es que lo que va a contar verdaderamente el día del referendo va a ser el desconocimiento general del contenido del tratado, al que sin duda contribuyen la extensión de su texto y la generalidad de muchos de sus preceptos; lo cual va a facilitar la manipulación de la ignorancia y la transformación del voto referendario en un voto típicamente electoral, de apoyo o crítica al partido en el gobierno. 
